\title{
Addressing the Challenges of Tuberculosis: A Brief Historical Account
}

\author{
Hussam W. Al-Humadi ${ }^{1,2 *}$, Rafal J. Al-Saigh ${ }^{1}$ and Ahmed W. Al-Humadi ${ }^{2}$ \\ ${ }^{1}$ Department of Pharmacology and Toxicology, Pharmacy College, University of Babylon, Babylon, Iraq, ${ }^{2}$ Laboratory of \\ Pharmacology, Medical School, National and Kapodistrian University of Athens, Athens, Greece
}

Tuberculosis (TB) is a highly contagious disease that still poses a threat to human health. Mycobacterium tuberculosis (MTB), the pathogen responsible for TB, uses diverse ways in order to survive in a variety of host lesions and to subsequently evade immune surveillance; as a result, fighting TB and its associated multidrug resistance has been an ongoing challenge. The aim of this review article is to summarize the historical sequence of drug development and use in the fight against TB, with a particular emphasis on the decades between World War II and the dawn of the twenty first century (2000).

Keywords: tuberculosis, history, treatment, anti-TB drugs, multidrug resistance, pharmaceutical innovation

\section{OPEN ACCESS}

Edited by:

Tilli Tansey,

Queen Mary University of London,

United Kingdom

Reviewed by:

Deepak Kumar Saini,

Indian Institute of Science, India

Alessandro Sanduzzi,

University of Naples Federico II, Italy

${ }^{*}$ Correspondence:

Hussam W. Al-Humadi alhumadi2010@gmail.com

Specialty section

This article was submitted to Experimental Pharmacology and Drug

Discovery,

a section of the journal

Frontiers in Pharmacology

Received: 01 March 2017 Accepted: 14 September 2017 Published: 26 September 2017

Citation:

Al-Humadi HW, Al-Saigh RJ and Al-Humadi AW (2017) Addressing the

Challenges of Tuberculosis: A Brief

Historical Account

Front. Pharmacol. 8:689.

doi: 10.3389/fphar.2017.00689

\section{INTRODUCTION}

Tuberculosis (TB) is a very old infectious disease, caused by Mycobacterium tuberculosis (MTB) (Dye and Williams, 2010). It's still the second most frequent cause of death in the world (WHO, 2014), reaching up to 10 million new cases every year (Dye and Williams, 2010); more interestingly, latent cases represent one third the world's population (WHO, 2014), with $10 \%$ of latent TB cases to progress to active infection (Selwyn et al., 1989), especially in diabetic or human immunodeficiency virus (HIV) positive patients, or those undergoing an immunotherapy (Barry et al., 2009). Active TB is characterized by chronic cough with bloody sputum, night sweats, fever and weight loss, while other organs (apart from the lungs) can be infected and cause a wide range of symptoms (Dolin Gerald et al., 2010).

TB bacilli are spread with the droplets of respiratory secretions that are associated with cough or sneezing of the infected person. The MTB can then invade and replicate within the endosomes of the pulmonary alveolar macrophages (Houben et al., 2006; Kumar et al., 2007) leading to clinically active disease in about 10\% of cases (Dye et al., 1999; WHO, 2009), while further growth of the remaining cases can be arrested by a competent immune response. However, in those with arrested cases, the bacilli are completely eradicated in about $10 \%$ of the individuals, with the remaining $90 \%$ entering a dormant or latent state in which there is a containment of the infection. As pathogens escape from the microbicidal action of the host immune cells (phagosome-lysosome fusion; MHC class I, class II, and CD1 molecules antigens; nitric oxide and other reactive nitrogen intermediates), latent $\mathrm{TB}$ and the dormant bacilli are reactivated with any serious disruption (decline) in the host immune state (HIV infection, diabetes mellitus, renal failure, chemotherapy and immunosuppressive therapy, malnutrition, etc.) that occurs (Dye et al., 1999; Corbett et al., 2003; Frieden et al., 2003; Wells et al., 2007; Dooley and Chaisson, 2009; WHO, 2009).

The unique clinical manifestations of MTB are attributed to the high lipid content of this pathogen (Southwick, 2007); the latter has an outer membrane lipid bilayer (Niederweis et al., 2010) and therefore, hematogenous transmission can also spread infection to more distant sites, such as peripheral lymph nodes, the kidneys, the brain, and even the bones (Harries, 2005; Herrmann and Lagrange, 2005; Kumar et al., 2007). 
The public health challenge of TB has been managed by a number of drugs and treatment strategies over the years, but this challenge has always been much bigger in certain parts of the world. The spreading of the HIV infection has been a major factor in managing the $\mathrm{TB}$ challenge, and so has been the increasing resistance of MTB strains to the high efficacy first line antiTB drugs (Table 1; WHO, 2009) which leads to the growing incidences of drug resistant strains: multiple drug resistant (MDR) and extensively drug resistant (XDR). These strains pose a significant threat, especially for immunocompromised patients who are significantly less likely to recover without the assistance of effective drugs. Other factors that may contribute in disease progression include poverty, population expansion, active transmission in overcrowded places (hospitals, prisons, and other public places), migration of individuals from highincidence countries due to wars or famine, drug abuse, social decay, homelessness (Frieden et al., 2003; Hill et al., 2004; Mathema et al., 2008) and technical problems like poor quality of detection, in addition to health status (old age, malnutrition, and medical conditions that compromise the immune system) (Corbett et al., 2003; Frieden et al., 2003; Wells et al., 2007; Dooley and Chaisson, 2009).

Furthermore, the unusual structure and chemical composition of the MTB cell wall (which hinders the entry of drugs and leads to drugs resistance) (Brennan and Nikaido, 1995) as well as the capability of the MTB cell to lie dormant at a low metabolic rate, in a deep location in pulmonary cavities or inside solid material that makes antibiotic penetration difficult. Finally, expensive, long-term therapy, disturbed therapeutic regimens, dosage variance and irregularity in follow up, form additional challenges for an effective TB management (Lawn and Zumla, 2011).

The aim of this review article is to summarize the historical sequence of drug development and use in the fight against TB, with a particular emphasis on the decades between World War II and the dawn of the twenty first century (2000).

\section{HISTORICAL SEQUENCES IN MANAGEMENT OF TB: BEFORE WORLD WAR II}

There is evidence of TB being present in humans since antiquity (Lawn and Zumla, 2011). MTB has been detected in the remnants of a bison in Wyoming that lived 17,000 years ago (Rothschild et al., 2001), while researchers have found tubercular decay in the spines of Egyptian mummies (3000-2400 BC) (Zink et al., 2003), and genetic studies suggested TB was present in America since around $100 \mathrm{AD}$ (Konomi et al., 2002). In Europe, TB had begun to rise between seventeenth and nineteenth century, in which it reached a peak level and caused about $25 \%$ of all deaths (Bloom, 1994). At that time, several measures had been taken including the improvement of life style and the encouragement of the infected people to enter sanatoria (McCarthy, 2001). However, $50 \%$ of those who entered sanatoria died within 5 years (McCarthy, 2001).
TABLE 1 | Classification of anti-tuberculosis (anti-TB) drugs according to WHO (2010).

\begin{tabular}{|c|c|c|c|}
\hline Lines & Grouping & Drugs & \\
\hline \multirow{6}{*}{$\begin{array}{l}\text { First-line } \\
\text { anti-TB drugs }\end{array}$} & \multirow[t]{6}{*}{ Group 1 (oral) } & \multicolumn{2}{|l|}{ Isoniazid (H/INH) } \\
\hline & & \multicolumn{2}{|c|}{ Rifampicin/rifampin (R/RIF) } \\
\hline & & \multicolumn{2}{|l|}{ Pyrazinamide (Z/PZA) } \\
\hline & & \multicolumn{2}{|l|}{ Ethambutol (E/EMB) } \\
\hline & & \multicolumn{2}{|l|}{ Rifapentine (P/RPT) } \\
\hline & & \multicolumn{2}{|l|}{ Rifabutin (RFB) } \\
\hline \multirow{17}{*}{$\begin{array}{l}\text { Second-line } \\
\text { anti-TB drugs }\end{array}$} & \multirow{5}{*}{$\begin{array}{l}\text { Group } 2 \\
\text { (injectable) }\end{array}$} & \multirow[t]{3}{*}{ Aminoglycosides } & Streptomycin (S/STM) \\
\hline & & & Kanamycin (KM) \\
\hline & & & Amikacin (AMK) \\
\hline & & \multirow[t]{2}{*}{ Polypeptides } & Capreomycin (CM) \\
\hline & & & Viomycin (VIM) \\
\hline & \multirow{5}{*}{$\begin{array}{l}\text { Group } 3 \text { (oral and } \\
\text { injectable; } \\
\text { fluoroquinolones) }\end{array}$} & \multicolumn{2}{|l|}{ Ciprofloxacin (cfx) } \\
\hline & & \multicolumn{2}{|l|}{ Levofloxacin (lfx) } \\
\hline & & \multicolumn{2}{|l|}{ Moxifloxacin (mfx) } \\
\hline & & \multicolumn{2}{|l|}{ Ofloxacin (OFX) } \\
\hline & & \multicolumn{2}{|l|}{ Gatifloxacin (GFX) } \\
\hline & Group 4 (oral) & \multicolumn{2}{|c|}{ Para-aminosalicylic acid (PAS) } \\
\hline & & \multicolumn{2}{|l|}{ Cycloserine (DCS) } \\
\hline & & \multicolumn{2}{|l|}{ Terizidone (TRD) } \\
\hline & & \multicolumn{2}{|l|}{ Ethionamide (ETO) } \\
\hline & & \multicolumn{2}{|l|}{ Prothionamide (PTO) } \\
\hline & & \multicolumn{2}{|l|}{ Thioacetazone (THZ) } \\
\hline & & \multicolumn{2}{|l|}{ Linezolid (LZD) } \\
\hline
\end{tabular}

\begin{tabular}{lll}
\hline Third-line & Group 5 (oral and & Clofazimine (CFZ) \\
anti-TB drugs & injectable) & Linezolid (LZD) \\
& & Amoxicillin plus clavulanate (AMX/CLV) \\
& Imipenem plus cilastatin (IPM/CLN) \\
& Clarithromycin (CLR)
\end{tabular}

On 24 March 1882, MTB was identified and described by Robert Koch; he was later honored with the Nobel Prize (1905) for this discovery (Nobel Foundation, 2014), the "TB World Day" was established on that date. Koch didn't pay attention for the similarity between bovine and human $\mathrm{TB}$, therefore, the recognition for $\mathrm{TB}$-infected milk as a way of $\mathrm{TB}$ transmission was delayed until the invention of the pasteurization process, that reduced it dramatically. Koch announced a glycerin extract of the TB bacilli as a "remedy" for TB in 1890, calling it "tuberculin." Even though, it was not effective, it was later adapted as a screening test for the presence of latent TB (Waddington, 2004).

In 1906, Albert Calmette and Camille Guérin achieved the first genuine success in immunization against TB by using attenuated bovine-strain TB. It was called the "bacille Calmette-Guérin" (BCG). This vaccine was first used on humans in 1921 in France (Bonah, 2005), but the vaccine got widespread acceptance in the US, Great Britain, and Germany only after World War II (Comstock, 1994). 
The discovery of penicillin initiated the war against various infectious microorganisms, and has set the basis for a greater motivation to discover other antibacterial and antimicrobial compounds for overcoming diseases like TB. The success of penicillin during World War II pushed researchers to study other molds (Aminov, 2010), one of them being Streptomyces griseus, found in chickens; as a result, streptomycin was successfully purified in 1943 and used as an anti-TB therapy in 1945 (Schatz et al., 1944; Kerantzas and Jacobs, 2017). Unfortunately, the overuse of streptomycin led to the development of drugresistance (Kerantzas and Jacobs, 2017), but the end of World War II saw major developments in pharmacology been established, and a number of drugs being developed and used against TB (Figure 1; Schatz et al., 1944; Wassersug, 1946).

\section{HISTORICAL SEQUENCES IN MANAGEMENT OF TB: AFTER WORLD WAR II}

In 1946, the Medical Research Council (MRC) TB Unit in the UK was established, and a clinical study designed for comparing streptomycin with bed rest vs. bed rest alone (Marshall, 1949) was launched. As expected, high clinical improvement was seen in streptomycin with bed rest in comparison to bed rest alone, however, a greater improvement was seen in the first 3 months, and many patients deteriorated later on due to the emergence of streptomycin resistance (Kerantzas and Jacobs, 2017).

Better results followed with the development of paraaminosalicyclic acid (PAS), which was an oral agent (unlike streptomycin) and could be used in combination with streptomycin (Lehmann, 1946; British Medical Journal, 1950; Fox et al., 1999; Williams, 2009). In 1950s, several anti-TB drugs with different mechanisms of action were discovered and developed, including PAS, isoniazid, pyrazinamide, cycloserine and kanamycin (Figure 1, Table 2). In 1951, streptomycin plus isoniazid were introduced as a TB therapy (Fox et al., 1999), while rifampicin (in 1960) allowed the shortening of TB therapy to 9 months when given with isoniazid, and to 6 months when given with pyrazinamide (American Thoracic Society, 2003). By the 1970s, five antibiotics were available against TB (Figure 1). Afterwards, the MRC TB Unit developed the current shortcourse therapeutic regimen (isoniazid, rifampicin, pyrazinamide and ethambutol) in collaboration with the United States Public Health Service.

Latent TB has been treated usually with a single antibiotic to prevent progressing to active TB disease (Menzies et al., 2011), while active TB is now treated with combinations of antibiotics in order to reduce the growing risk of antibiotic resistance (Lawn and Zumla, 2011). Directly observed therapyshort course (DOTS) is currently recommended by the WHO as an effort to reduce the number of people not appropriately taking antibiotics (Volmink and Garner, 2007; Liu et al., 2008; Mainous and Pomeroy, 2010). When MDR-TB is detected, treatment with at least four effective antibiotics for 18-24 months is recommended (Lawn and Zumla, 2011). A person with fullysusceptible MTB may develop secondary resistance because of inadequate therapy, or using low-quality medication (O'Brien, 1994).

\section{DRUG RESISTANCE FOR TB}

More than $50 \%$ of the world's MDR-TB cases are found in India and China, where about $5.4 \%$ of MDR-TB cases progress to XDR-TB (WHO, 2010). The MDR-TB treatment is a combination of 8-10 drugs for 18-24 months (Gandhi et al., 2010). Resistance to the two most effective first-line anti-TB drugs, rifampicin and isoniazid, is known as MDR$\mathrm{TB}$, while resistance to three or more of the six classes of second-line drugs is known as XDR-TB (Table 1; CDC, 2006); the latter has been identified in more than $90 \%$ of the world's

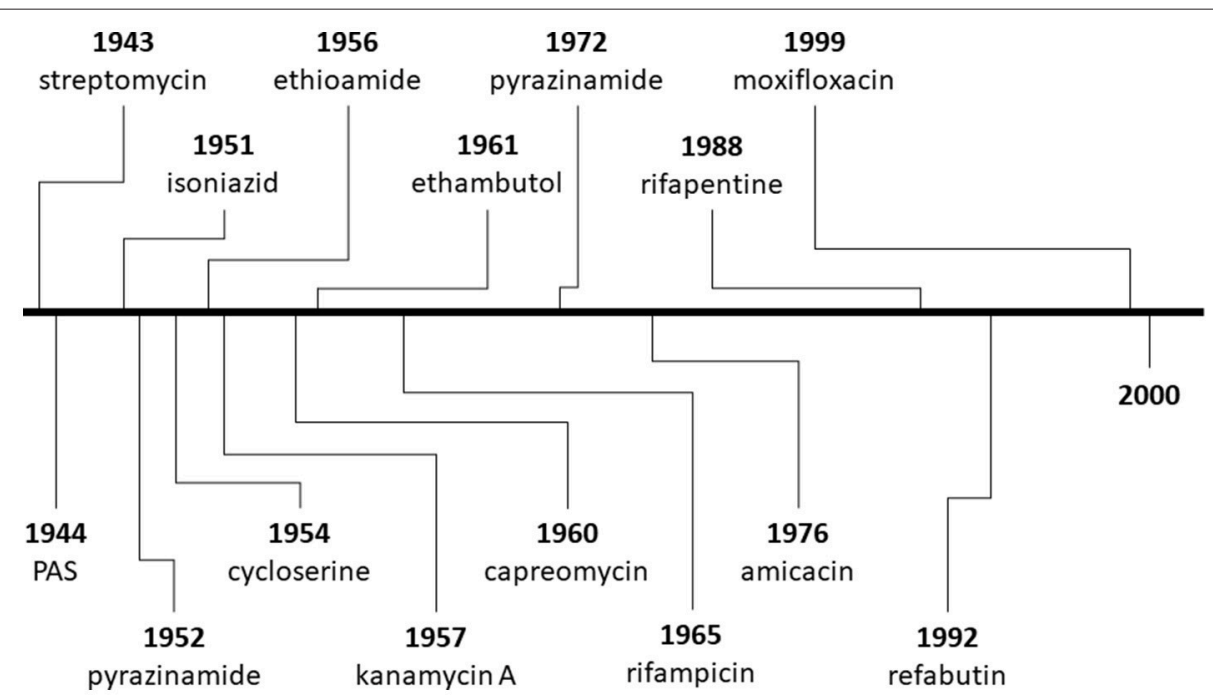

FIGURE 1 | Timeline of the discovery of major compounds used for the treatment of tuberculosis (TB) from the Second World War until 2000. 


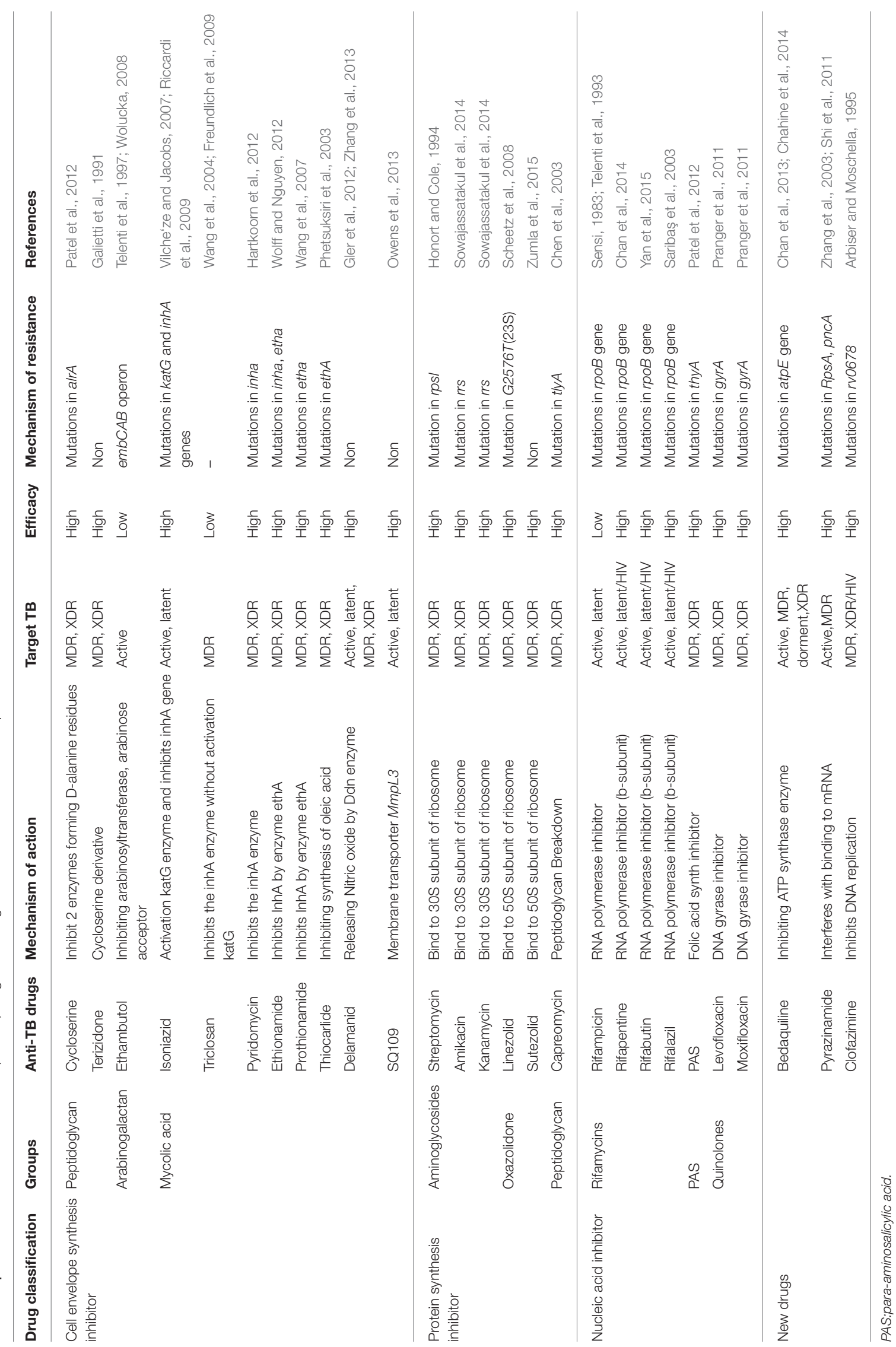


countries (Akachi et al., 2012). Total drug-resistant to all currently used drugs (McKenna, 2012) was first observed in Italy (2003) (Migliori et al., 2007), and had also been reported in Iran and India (Velayati et al., 2009; Akachi et al., 2012), but not widely reported until 2012 (WHO, 2006; Migliori et al., 2007).

MTB strains undergo spontaneous mutations that lead to resistance of one or more anti-TB drug (David, 1970). Thus, the exposure of MTB population to a single anti-TB drug could inhibit its growth but not completely eradicate it, therefore, regrowth and mutations leading to progressive drug resistance, these mutated genes are eventually triggering continuous proliferation of the bacilli and recurrence of symptoms, which is called "the fall and rise phenomenon" (Espinal, 2004). Hence, low drug levels due to insufficient drug bioavailability or from malabsorption (e.g., in HIV patients) have emerged in the etiology and mechanism of anti-TB drug resistance. Furthermore, continuous use of old anti-TB regimens may not target specific populations of MTB under certain circumstances that hardly act in acidic, or hypoxic conditions within caseous foci or inside macrophages (Mitchison, 1998). The resistance also developed independently for each drug in combined anti-TB regimens at a specific time through mutation processes.

We now know that MDR and XDR-TB infections' danger can be overcome by preventing resistance of already sensitive antiTB drug within the combination regimen (Morris et al., 1995). As some studies reported, the resistance arises from replicating bacilli, while non-replicating bacilli do not undergo mutation and no resistance can be developed. Thus, minimizing the drug resistance can be performed by extending the therapeutic duration and subjecting MTB to drugs with longer half-lifes (Gumbo et al., 2009). Some newest agents that are used for MDR$\mathrm{TB}$, such as bedaquiline, are tentatively recommended (Chahine et al., 2014). Ineffective and inadequate anti-TB treatment could fail to achieve goals in about $30 \%$ of MDR-TB patients (Mitnick et al., 2003). The treatment of XDR-TB is very difficult, because XDR-TB bacilli are resistant for more drugs other than isoniazid and rifampicin, including fluoroquinolones and aminoglycosides (Ma et al., 2010).

The drug-resistant TB can be predicted in TB patients with unsuccessful therapy (relapse) or those who are in close contacts with MDR-TB patients (Becerra et al., 2011). Therefore, a 5 month treatment with positive sputum smear or culture is closely attributed to MDR-TB strains (Lew et al., 2008), and in such cases, several molecular methods for diagnosis of MDR-TB are enrolled, including the Xpert MTB/RIF, which is currently available for the detection of rifampicin resistance (Menzies et al., 2009; Sharma et al., 2015).

The last two decades have witnessed an ongoing effort to understand the molecular bases for anti-TB resistance and to further investigate the genetic traits in MDR- and XDRTB strains (Nachega and Chaisson, 2003). Mutated genes that associated with MDR- and XDR-TB are described in Table 2, which are classified as first line anti-TB drugs resistance, that starts with isoniazid resistance; the latter is connected to alterations in the catalase-peroxidase gene (katG), the inhA gene, which encodes in an enzyme involved in mycolic acid biosynthesis (Vilche'ze and Jacobs, 2007; Riccardi et al., 2009). Rifampin resistance, including its derivatives (rifapentine, rifabutin and rifalazil) resistance, is associated with genetic mutations in rpoB, which encodes the RNA polymerase $\beta$ subunit (Sensi, 1983; Telenti et al., 1993; Saribaş et al., 2003; Chan et al., 2014; Yan et al., 2015). Pyrazinamide resistance is linked to mutations in pncA, that eliminates the pyrazinamidase/nicotinamidase activity (Zhang et al., 2003; Shi et al., 2011). Ethambutol resistance is conferred to genetic mutations with the embCAB operon, which facilitates production of arabinosyl transferase (Telenti et al., 1997; Wolucka, 2008). In spite of the role of the second line drugs to overcome the MDR that linked with the first line drugs, second line drugs are also linked with genetic mutations like the first line agents: streptomycin resistance which is associated with mutations in the rpsL, ribosomal S12 protein, and rrs, 16S rRNA gene (Honort and Cole, 1994); kanamycin and amikacin resistance are closely linked to genetic mutations of streptomycin (Sowajassatakul et al., 2014); while capreomycin resistance is attributed to mutagenesis of the tlyA gene, which has homology to rRNA methyltransferases (Chen et al., 2003). Quinolones resistance (like levofloxacin and moxifloxacin) is associated with mutation of gyrA gene encoding DNA gyrase (Pranger et al., 2011). Ethionamide resistance is linked to inhA mutations, in addition to cross-resistance between isoniazid and ethionamide in mutations of the etaA (ethA) gene, which is responsible for ethionamide activation (Wolff and Nguyen, 2012). The resistance to PAS is linked to mutations within the thyA gene, which produces thymidylate synthase A (Patel et al., 2012), while cycloserine resistance is conferred with activation of the alrA gene as $\mathrm{D}$-alanine racemase encoding, which causes increased over expression of alrA (Chacon et al., 2002).

Advances in MTB targeting have emerged through the exploration of the genome sequence of MTB (Cole et al., 1998), but unfortunately this approach gave little success (Payne et al., 2007 ) as it is not predicting the drug ability of the discovered new agent (Working Group on New TB Drugs, 2010). Genome sequencing of MTB, identification of the essential signaling and metabolic pathways, assessment of physicochemical properties of the MTB and other methods are still employed in order to discover newer agents with high specificity and less toxicity with good efficacy. In parallel, reengineering and repositioning of the old known drugs have been adapted to achieve better results in therapy, but the challenges of the resistance still threaten this goal and the discovering of the new agents remain the main approach to counteract the deterioration in situation over the world (Koul et al., 2011).

\section{IMMUNOMODULATORY AND REPURPOSING DRUGS AGAINST TB}

An efficient and competent host immune system is crucial for the eradication of an MTB infection and/or containment of latent TB infection (Migliori and Huggett, 2009; Zumla et al., 2012; Wallis et al., 2013). The stability of latent TB state is achieved by MTB ability to attenuate and evade host mycobactericidal 
responses. Inadequate immunity leads to MTB multiplication and clinical symptoms' development. Acceleration of the host inflammatory response may lead to tissue destruction; therefore, several agents are being used in order to manipulate and reduce the destructive inflammatory responses, or augment protective immunity to enhance recovery and minimize the duration of therapy (Subbian et al., 2011; Tobin et al., 2012).

In experimental animals, the role of pro-inflammatory and anti-inflammatory eicosanoids in the process of regulating tumor necrosis factor- $\alpha$ levels (Tobin et al., 2012) and in tailoring TB treatment, depends on the host genotype (Skerry et al., 2012). Administered prophylactically or therapeutically, the ABL family tyrosine kinase inhibitor, such as imatinib, reduced the MTB load and the granulomatous lesions in MTB-infected organs and was also effective against a rifampicin-resistant strain of MTB when co-administered with current first-line TB drugs (Napier et al., 2012). Furthermore, using generic, non-steroidal anti-inflammatory (NSAIDs) and analgesic drugs as an adjunct therapy in experimental animal models, has a wide clinical distributed (Ivanyi and Zumla, 2013). NSAIDs can reduce MTB load and alleviate lung damage in mice (Vilaplana et al., 2013), and they show anti-TB activity in phenotypical assays (Guzman et al., 2013).

Both verapamil (a calcium-channel blocker) and reserpine (an adrenergic neuron blocking agent) have efflux pump inhibitory properties that could decrease macrophage-induced drug tolerance (Amaral et al., 2007; Adams et al., 2011); as a result, both could be added to anti-TB regimen to decrease the duration of curative therapy. Ivermectin is an anti-nematode agent that also has bactericidal activity against MTB (Lim et al., 2013). Cilostazol and sildenafil-as phosphodiesterase inhibitors-could be added to the anti-TB regimen, as they improve the resolution of tissue pathology, accelerating MTB clearance and diminishing therapeutic period (Maiga et al., 2012). Lansoprazole, a well-known proton-pump inhibitor, was also found to be effective against intracellular MTB by targeting its cytochrome bcl complex through intracellular sulfoxide reduction (metabolite enzyme) to lansoprazole sulfide; this metabolite enzyme is crucial for the bacterium to produce energy, thereby killing it off (Rybniker et al., 2015). Metformin, which is a drug used for the treatment of type 2 diabetes, acts as inhibitor to a mitochondrial complex which is similar to bacterial $\mathrm{NDH}$ complex, thus enhancing the targeting of an anti-TB drug toward intracellular MTB (Cole et al., 1998; Vashisht and Brahmachari, 2015). Finally, chemical and biological immunomodulatory agents have also been evaluated to accelerate host immune responses in anti-TB therapy (Uhlin et al., 2012), with MDR-TB cure rate enhancement, prevention of recurrence and shortening therapy duration occurring as a result.

\section{TB/HIV CO-INFECTION}

It is known that the concomitant use of anti-retroviral therapy (ART) with the treatment of drug-susceptible pulmonary TB improves survival rates in HIV-infected individuals. However, treatment of $\mathrm{TB}$ in such patients is complicated, due to potential drug interactions and the risk of developing "immune reconstitution inflammatory syndrome” (Gengiah et al., 2011). The important drug interactions occur between the rifamycins and the protease inhibitors as well as non-nucleoside reverse transcriptase inhibitor drugs. Rifamycin derivatives (rifampicin, rifabutin and rifapentine) induce liver enzymes and reduce serum concentrations of protease inhibitors, such as indinavir, nelfinavir, saquinavir, ritonavir, amprenavir, atzanavir, and fosamprenavir. Rifabutin is the least potent inducer of CYP3A (Weber et al., 2001) and rifapentine falls in between rifampicin and rifabutin in its capacity to induce CYP3A. Rifapentine is not recommended for the treatment of TB in HIV-infected individuals because of the increased rate of acquired rifamycin resistance (Dheda et al., 2010). Rifabutin is used as a substitute for rifampicin in the treatment of active TB in patients receiving ART. On the other hand, delaying initiation of ART until TB treatment is completed in HIV-infected individuals significantly increases mortality across the spectrum of immunodeficiency. Clinical trials have reported that early ART in TB patients coinfected with HIV decreases mortality (Havlir et al., 2011). The World Health Organization recommends that ART should be started within the first 8 weeks of initiating TB treatment (Blanc et al., 2011; De Cock and El-Sadr, 2013), while the optimal timing of initiating ART in patients with TB-HIV co-infection in SubSaharan Africa remains an urgent research priority (De Cock and El-Sadr, 2013).

\section{PREVENTION}

The prevention and control of TB depend primarily on vaccination of infants and appropriate diagnosis and treatment of active cases (Lawn and Zumla, 2011). The US Preventive Services Task Force (USPSTF) recommends screening high risk people for latent TB with either tuberculin skin tests or interferon-gamma release assays (Bibbins-Domingo et al., 2016). The only available vaccine since 1921 is BCG (McShane, 2011). In children, BCG decreases the risk of getting the infection by $20 \%$ and the risk of infection turning into disease by nearly 60\% (Roy et al., 2014). It is the most widely used vaccine worldwide, with more than $90 \%$ of all children being vaccinated (Lawn and Zumla, 2011). However, it should be noted that the immunity induced by the vaccine decreases after about 10 years (Lawn and Zumla, 2011). Moreover, as $\mathrm{TB}$ is uncommon in most of Canada, the UK, and the USA; BCG is administered only to those at high risk (CDC, 2006; Teo and Shingadia, 2006; Public Health Agency of Canada, 2010). Finally, the drawback of the BCG vaccine is making the tuberculin skin test result false positive; therefore, this test not widely used in screening for TB anymore (Teo and Shingadia, 2006).

\section{AUTHOR CONTRIBUTIONS}

All authors listed have made a substantial, direct and intellectual contribution to the work, and approved it for publication. 


\section{REFERENCES}

Adams, K. N., Takaki, K., Connolly, L. E., Wiedenhoft, H., Winglee, K., Humbert, O., et al (2011). Drug tolerance in replicating mycobacteria mediate macrophage-induced efflux mechanism. Cell 145, 39-53. doi: 10.1016/j.cell.2011.02.022

Akachi, Y., Zumla, A., and Atun, R. (2012). Investing in improved performance of national tuberculosis programs reduces the tuberculosis burden: analysis of 22 high-burden countries, 2002-2009. J. Infect. Dis. 15, S284-S292. doi: 10.1093/infdis/jis189

Amaral, L., Martins, M., and Viveiros, M. (2007). Enhanced killing of intracellular multidrug-resistant Mycobacterium tuberculosis by compounds that affect the activity of efflux pumps. J. Antimicrob. Chemother. 59, 1237-1246. doi: $10.1093 / \mathrm{jac} / \mathrm{dkl} 500$

American Thoracic Society (2003). Treatment of tuberculosis. Am. J. Respir. Crit. Care Med. 167, 603-662. doi: 10.1164/rccm.167.4.603

Aminov, R. I. (2010). A brief history of the antibiotic era: lessons learned and challenges for the future. Front. Microbiol. 1:134. doi: $10.3389 /$ fmicb.2010.00134

Arbiser, J. L., and Moschella, S. L. (1995). Clofazimine: a review of its medical uses and mechanisms of action. J. Am. Acad. Dermatol. 32(2 Pt 1), 241-247. doi: 10.1016/0190-9622(95)90134-5

Barry, C. E. III., Boshoff, H., Dartois,V., Dick, T., Ehrt, S., Flynn, J., et al. (2009). The spectrum of latent tuberculosis: rethinking the biology and intervention strategies. Nat. Rev. Microbiol. 7, 845-855. doi: 10.1038/nrmicro2236

Becerra, M. C., Appleton, S. C., Franke, M. F., Chalco, K., Arteaga, F., Bayona, J., et al. (2011). Tuberculosis burden in households of patients with multidrugresistant and extensively drug-resistant tuberculosis: a retrospective cohort study. Lancet 377, 147-152. doi: 10.1016/S0140-6736(10)61972-1

Bibbins-Domingo, K., Grossman, D. C., Curry, S. J., Bauman, L., Davidson, K. W., Epling, J. W., et al (2016). Screening for latent tuberculosis infection in Adults. JAMA 316, 962-969. doi: 10.1001/jama.2016.11046

Blanc, F. X., Sok, T., Laureillard, D., Borand, L., Rekacewicz, C., Nerrienet, E., et al. (2011). CAMELIA (ANRS 1295-CIPRA KH001) Study team. Earlier versus later start of antiretroviral therapy in HIV-infected adults with tuberculosis. $N$. Engl. J. Med. 365, 1471-1481. doi: 10.1056/NEJMoa1013911

Bloom, B. R. (1994). Tuberculosis: Pathogenesis, Protection, and Control. Washington, DC: American Society for Microbiol Press.

Bonah, C. (2005). The "experimental stable" of the BCG vaccine: safety, efficacy, proof, and standards, 1921-1933. Stud. Hist. Philos. Biol. Biomed. Sci. 36, 696-721. doi: 10.1016/j.shpsc.2005.09.003

Brennan, P. J., and Nikaido, H. (1995). The envelope of mycobacteria. Annu. Rev. Biochem. 64, 29-63. doi: 10.1146/annurev.bi.64.070195.000333

British Medical Journal (1950). Treatment of pulmonary tuberculosis with streptomycin and para-amino-salicylic acid; a medical research council investigation. Br. Med. J. 2, 1073-1085. doi: 10.1136/bmj.2.4688.1073

Centers for Disease Control and Prevention (CDC) (2006). Emergence of Mycobacterium tuberculosis with extensive resistance to second-line drugsworldwide, 2000-2004. Morb. Mortal Wkly. Rep. 55, 301-305.

Chacon, O., Feng, Z., Harris, N. B., Caceres, N. E., Adams, L. G., and Barletta, R. G. (2002). Mycobacterium smegmatis Dalanine racemase mutants are not dependent on Dalanine for growth. Antimicrob. Agents Chemother. 46, 47-54. doi: 10.1128/AAC.46.2.47-54.2002

Chahine, E. B., Karaoui, L. R., and Mansour, H. (2014). Bedaquiline: a novel diarylquinoline for multidrug-resistant tuberculosis. Ann. Pharmacother. 48, 107-115. doi: 10.1177/1060028013504087

Chan, B., Khadem, T. M., and Brown, J. (2013). A review of tuberculosis: focus on bedaquiline. Am. J. Health Syst. Pharm. 70, 1984-1994. doi: 10.2146/ajhp130199

Chan, J. G., Bai, X., and Traini, D. (2014). An update on the use of rifapentine for tuberculosis therapy, expert opin. Drug Deliv. 11, 421-431. doi: $10.1517 / 17425247.2014 .877886$

Chen, Q. L., Chen, L., and Yin, J. J. (2003). A study on the clinical efficacy of a combination regimen with levofloxacin and capreomycin in the treatment of multi-drug resistant pulmonary tuberculosis. Zhonghua Jie $\mathrm{He} \mathrm{He} \mathrm{Hu} \mathrm{Xi} \mathrm{Za}$ Zhi. 26, 454-457.

Cole, S. T., Brosch, R., Parkhill, J., Garnier, T., Churcher, C., Harris, D., et al. (1998). Deciphering the biology of Mycobacterium tuberculosis from the complete genome sequence. Nature 393, 537-544. doi: 10.1038/31159
Comstock, G. (1994). The international tuberculosis campaign: a pioneering venture in mass vaccination and research. Clin. Infect. Dis. 19, 528-540. doi: $10.1093 /$ clinids/19.3.528

Corbett, E. L., Watt, C. J., Walker, N., Maher, D., Williams, B. G., Raviglione, M. C., et al. (2003). The growing burden of tuberculosis: global trends and interactions with the HIV epidemic. Arch. Intern. Med. 163, 1009-1021. doi: 10.1001/archinte.163.9.1009

David, H. L. (1970). Probability distribution of drug-resistant mutants in unselected populations of Mycobacterium tuberculosis. Appl. Microbiol. 20, 810-814.

De Cock, K. M., and El-Sadr, W. M. (2013). When to start ART in Africa-an urgent research priority. N. Engl. J. Med. 368, 886-889. doi: 10.1056/NEJMp1300458

Dheda, K., Shean, K., Zumla, A., Badri, M., Streicher, E. M., Page-Shipp, L., et al. (2010). Early treatment outcomes and HIV status of patients with extensively drug-resistant tuberculosis in South Africa: a retrospective cohort study. Lancet 375, 1798-1807. doi: 10.1016/S0140-6736(10)60492-8

Dolin Gerald, L., Mandell John, E., and Bennett, R. (2010). Mandell, Douglas, and Bennett's Principles and Practice of Infectious Diseases, 7th Edn. Philadelphia, PA: Churchill Livingstone/Elsevier.

Dooley, K. E., and Chaisson, R. E. (2009). Tuberculosis and diabetes mellitus: convergence of two epidemics. Lancet Infect. Dis. 9, 737-746. doi: 10.1016/S1473-3099(09)70282-8

Dye, C., and Williams, B. G. (2010). The population dynamics and control of tuberculosis. Science 328, 856-861. doi: 10.1126/science.1185449

Dye, C., Scheele, S., Dolin, P., Pathania, V., and Raviglione, M. C. (1999). Consensus statement. Global burden of tuberculosis: estimated incidence, prevalence, and mortality by country. WHO global surveillance and monitoring project. JAMA 282, 677-686. doi: 10.1001/jama.282.7.677

Espinal, M. (2004). "What is the 'fall and rise' phenomenon and the 'sequential regimen' mechanism?" in Toman's Tuberculosis: Case Detection, Treatment, and Monitoring-Questions and Answers 2nd Edn, ed T. Frieden (Geneva: World Health Organization), 200-202.

Fox, W., Ellard, G. A., and Mitchison, D. A. (1999). Studies on the treatment of tuberculosis undertaken by the British Medical Research Council Tuberculosis Units, 1946-1986, with relevant subsequent publications. Int. J. Tuberc. Lung. Dis. 3, S231-S279.

Freundlich, J. S., Wang, F., Vilchèze, C., Gulten, G., Langley, R., Schiehser, G. A., et al. (2009). Triclosan derivatives: towards potent inhibitors of drug-sensitive and drug-resistant Mycobacterium tuberculosis. Chem. Med. Chem. 4, 241-248. doi: $10.1002 / \mathrm{cmdc} .200800261$

Frieden, T. R., Sterling, S. S., Munsiff, C. J., Watt, C., and Dye, C. (2003). Tuberculosis. Lancet 362, 887-899. doi: 10.1016/S0140-6736(03)14333-4

Galietti, F., Giorgis, G. E., Oliaro, A., Boaro, D., Ardizzi, A., Barberis, S., et al. (1991). Tolerability to terizidone (TZ) in the treatment of pulmonary tuberculosis in dialyzed patients. Minerva Med. 82, 477-481.

Gandhi, N. R., Nunn, P., Dheda, K., Schaaf, H. S., Zignol, M., van Soolingen, D., et al. (2010). Multidrug-resistant and extensively drug-resistant tuberculosis: a threat to global control of tuberculosis. Lancet 375, 1830-1843. doi: 10.1016/S0140-6736(10)60410-2

Gengiah, T. N., Gray, A. L., Naidoo, K., and Karim, Q. A. (2011). Initiating antiretrovirals during tuberculosis treatment: a drug safety review. Expert Opin. Drug Saf. 10, 559-574. doi: 10.1517/14740338.2011.546783

Gler, M. T., Skripconoka, V., Sanchez-Garavito, E., Xiao, H., Cabrera-Rivero, J. L., Vargas-Vasquez, D. E., et al. (2012). Delamanid for multidrugresistant pulmonary tuberculosis. N. Engl. J. Med. 366, 2151-2160. doi: 10.1056/NEJMoa1112433

Gumbo, T., Dona, C. S., Meek, C., and Leff, R. (2009). Pharmacokineticspharmacodynamics of pyrazinamide in a novel in vitro model of tuberculosis for sterilizing effect: a paradigm for faster assessment of new antituberculosis drugs. Antimicrob. Agents Chemother. 53, 3197-3204. doi: 10.1128/AAC.01681-08

Guzman, J. D., Evangelopoulos, D., Gupta, A., Birchall, K., Mwaigwisya, S., Saxty, B., et al. (2013). Antitubercular specifi c activity of ibuprofen and the other 2-arylpropanoic acids using the HT-SPOTi whole-cell phenotypic assay. BMJ Open 3:e002672. doi: 10.1136/bmjopen-2013-002672

Harries, A. (2005). TB/HIV a Clinical Manual, 2nd Edn. Geneva: World Health Organization. 
Hartkoorn, R. C., Sala, C., Neres, J., Pojer, F., Magnet, S., Mukherjee, R., et al. (2012). Towards a new tuberculosis drug: pyridomycin - nature's isoniazid. EMBO Mol. Med. 4, 1032-1042. doi: 10.1002/emmm.201201689

Havlir, D. V., Kendall, M. A., Ive, P., Kumwenda, J., Swindells, S., Qasba, S. S., et al. (2011). Timing of antiretroviral therapy for HIV-1 infection and tuberculosis. N. Engl. J. Med. 365, 1482-1491. doi: 10.1056/NEJMoa1013607

Herrmann, J., and Lagrange, P. (2005). Dendritic cells and Mycobacterium tuberculosis: which is the Trojan horse? Pathol. Biol. 53, 35-40. doi: 10.1016/j.patbio.2004.01.004

Hill, P. C., Brookes, R. H., Fox, A., Fielding, K., Jeffries, D. J., Jackson-Sillah, D., et al. (2004). Large-scale evaluation of enzyme-linked immunospot assay and skin test for diagnosis of Mycobacterium tuberculosis infection against a gradient of exposure in The Gambia. Clin. Infect. Dis. 38, 966-973. doi: $10.1086 / 382362$

Honort, N., and Cole, S. T. (1994). Streptomycin resistance in mycobacteria. Antimicrob. Agents Chemother. 38, 238-242. doi: 10.1128/AAC.38.2.238

Houben, E., Nguyen, L., and Pieters, J. (2006). Interaction of pathogenic mycobacteria with the host immune system. Curr. Opin. Microbiol. 9, 76-85. doi: 10.1016/j.mib.2005.12.014

Ivanyi, I., and Zumla, A. (2013). Non-steroidal anti-inflammatory drugs for adjunctive tuberculosis treatment. J. Infect. Dis. 208, 185-188. doi: 10.1093/infdis/jit153

Kerantzas, C. A., and Jacobs, W. R. Jr. (2017). Origins of combination therapy for tuberculosis: lessons for future antimicrobial development and application. MBio 8, e01586-e01516. doi: 10.1128/mBio.01586-16

Konomi, N., Lebwohl, E., Mowbray, K., Tattersall, I., and Zhang, D. (2002). Detection of mycobacterial DNA in andean mummies. J. Clin. Microbiol. 40, 4738-4740. doi: 10.1128/JCM.40.12.4738-4740.2002

Koul, A., Arnoult, E., Lounis, N., Guillemont, J., and Andries, K. (2011). The challenge of new drug discovery for tuberculosis. Nature 469, 483-490. doi: 10.1038/nature09657

Kumar, V., Abbas, A. K., Fausto, N., and Mitchell, R. N. (2007). Robbins Basic Pathology 8th Edn. Philadelphia, PA: Saunders Elsevier.

Lawn, S. D., and Zumla, A. I. (2011). Tuberculosis. Lancet 378, 57-72. doi: 10.1016/S0140-6736(10)62173-3

Lehmann, J. (1946). Para-aminosalicylic acid in the treatment of tuberculosis. Lancet 1:15. doi: 10.1016/S0140-6736(46)91185-3

Lew, W., Pai, M., Oxlade, O., Martin, D., and Menzies, D. (2008). Initial drug resistance and tuberculosis treatment outcomes: systematic review and meta-analysis. Ann. Intern. Med. 149, 123-134. doi: 10.7326/0003-4819-149-2-200807150-00008

Lim, L. E., Vilchèze, C., Ng, C., Jacobs, W. R., Ramón-García, S. Jr. and Thompson, C. J. (2013). Anthelmintic avermectins kill M tuberculosis, including multidrug-resistant clinical strains. Antimicrob. Agents Chemother. 57, 1040-1046. doi: 10.1128/AAC.01696-12

Liu, Q., Abba, K., Alejandria, M. M., Balanag, V. M., Berba, R. P., and Lansang, M. A. (2008). Liu, Qin, edition. reminder systems and late patient tracers in the diagnosis and management of tuberculosis. Cochrane Database Syst. Rev. 8:CD006594. doi: 10.1002/14651858.CD006594.pub2

Ma, Z., Lienhardt, C., McIlleron, H., Nunn, A. J., and Wang, X. (2010). Global tuberculosis drug development pipeline: the need and the reality. Lancet 375 , 2100-2109. doi: 10.1016/S0140-6736(10)60359-9

Maiga, M., Agarwal, N., Ammerman, N. C., Gupta, R., Guo, H., Maiga, M. C., et al. (2012). Successful shortening of tuberculosis treatment using adjuvant host-directed therapy with FDA-approved phosphodiesterase inhibitors in the mouse model. PLoS ONE 7:e30749. doi: 10.1371/journal.pone. 0030749

Mainous III, A. G., and Pomeroy, C. (eds) (2010). Management of Antimicrobials in Infectious Diseases: Impact of Antibiotic Resistance. Totowa, NJ: Humana Press.

Marshall, G. (1949). Streptomycin in the treatment of pulmonary tuberculosis. A medical research council investigation. BMJ 1, 382-386.

Mathema, B., Kurepina, N., Fallows, D., and Kreiswirth, B. N. (2008). Lessons from molecular epidemiology and comparative genomics. Semin. Respir. Crit. Care Med. 29, 467-480. doi: 10.1055/s-0028-1085699

McCarthy, O. R. (2001). The key to the sanatoria. J. R. Soc. Med. 94, 413-417.

McKenna, M. (2012). Totally resistant TB: earliest cases in Italy. Science. Available online at: https://www.wired.com/2012/01/tdr-first-italy/
McShane, H. (2011). Tuberculosis vaccines: beyond bacille CalmetteGuérin. Philos. Trans. R. Soc. London. B Biol. Sci. 366, 2782-2789. doi: 10.1098/rstb.2011.0097

Menzies, D., Al Jahdali, H., and Al Otaibi, B. (2011). Recent developments in treatment of latent tuberculosis infection. Indian J. Med. Res. 133, 257-266.

Menzies, D., Benedetti, A., Paydar, A., Martin, I., Royce, S., Pai, M., et al. (2009). Effect of duration and intermittency of rifampin on tuberculosis treatment outcomes: a systematic review and meta-analysis. PLoS Med. 6:e1000146. doi: 10.1371/journal.pmed.1000146

Migliori, G. B., and Huggett, J. (2009). Tuberculosis: a comprehensive clinical reference. Eur. Res. J. 34:78.

Migliori, G. B., De Iaco, G., Besozzi, G., Centis, R., and Cirillo, D. M. (2007). First tuberculosis cases in Italy resistant to all tested drugs. Euro surveillance: bulletin Européen sur les maladies transmissibles. Eur. Commun. Dis. Bull. 12, e070517-e070511.

Mitchison, D. A. (1998). How drug resistance emerges as a result of poor compliance during short course chemotherapy for tuberculosis. Int. J. Tuberc. Lung. Dis. 2, 10-15.

Mitnick, C., Bayona, J., Palacios, E., Shin, S., Furin, J., Alcántara, F., et al. (2003). Community-based therapy for multidrug-resistant tuberculosis in Lima, Peru. N. Engl. J. Med. 348, 119-128. doi: 10.1056/NEJMoa022928

Morris, S., Bai, G. H., Suffys, P., Portillo-Gomez, L., Fairchok, M., and Rouse, D. (1995). Molecular mechanisms of multiple drug resistance in clinical isolates of Mycobacterium tuberculosis. J. Infect. Dis. 171, 954-960. doi: 10.1093/infdis/171.4.954

Nachega, J. B., and Chaisson, R. E. (2003). Tuberculosis drug resistance: a global threat. Clin. Infect. Dis. 36, S24-S30. doi: 10.1086/344657

Napier, R. J., Rafi, W., Cheruvu, M., Powell, K. R., Zaunbrecher, M. A., Bornmann, W., et al. (2012). Imatinib-sensitive tyrosine kinases regulate mycobacterial pathogenesis and represent therapeutic targets gainst tuberculosis. Cell Host Microbe 10, 475-485. doi: 10.1016/j.chom.2011.09.010

Niederweis, M., Danilchanka, O., Huff, J., Hoffmann, C., and Engelhardt, H. (2010). Mycobacterial outer membranes: in search of proteins. Trends Microbiol. 18, 109-1016. doi: 10.1016/j.tim.2009.12.005

Nobel Foundation (2014). The Nobel Prize in Physiology or Medicine 1905. Nobelprize.org. Nobel Media AB 2014. Available online at: http://www. nobelprize.org/nobel_prizes/medicine/laureates/1905/ (Accessed September $21,2017)$.

O'Brien, R. (1994). Drug-resistant tuberculosis: etiology, management and prevention. Semin. Respir. Infect. 9, 104-112.

Owens, C. P., Chim, N., Graves, A. B., Harmston, C. A., Iniguez, A., Contreras, H., et al. (2013). The Mycobacterium tuberculosis secreted protein Rv0203 transfers heme to membrane proteins MmpL3 and MmpL11, J. Biol. Chem. 288, 21714-21728. doi: 10.1074/jbc.M113.453076

Patel, D. M., Patel, S. D., Jaiswal, P. S., and Brahmbhatt, K. J. (2012). Drug Resistant Mycobacterium tuberculosis and new drug development. Int. J. Drug Dev. Res. 4, 76-91.

Payne, D. J., Gwynn, M. N., Holmes, D. J., and Pompliano, D. L. (2007). Drugs for bad bugs: confronting the challenges of antibacterial discovery. Nat. Rev. Drug Discov. 6, 29-40. doi: 10.1038/nrd2201

Phetsuksiri, B., Jackson, M., Scherman, H., McNeil, M., Besra, G. S., Baulard, A. R., et al. (2003). Unique mechanism of action of the thiourea drug isoxyl on Mycobacterium tuberculosis. J. Biol. Chem. 278, 53123-53130. doi: 10.1074/jbc.M311209200

Pranger, A. D., van Altena, R., Aarnoutse, R. E., van Soolingen, D., Uges, D. R., Kosterink, J. G., et al. (2011). Evaluation of moxifloxacin for the treatment of tuberculosis: 3 years of experience. Eur. Respir. J. 38, 888-894. doi: $10.1183 / 09031936.00176610$

Public Health Agency of Canada (2010). BCG Vaccine Usage in Canada-Current and Historical. Ottawa, ON: Public Health Agency of Canada (Accessed Dec 30, 2011).

Riccardi, G., Pasca, M. R., and Buroni, S. (2009). Mycobacterium tuberculosis: drug resistance and future perspectives. Future Microbiol. 4, 597-614. doi: $10.2217 / \mathrm{fmb} .09 .20$

Rothschild, B. M., Martin, L. D., Lev, G., Bercovier, H., Bar-Gal, G. K., Greenblatt, C., et al. (2001). Mycobacterium tuberculosis complex DNA from an extinct bison dated 17,000 years before the present. Clin. Infect. Dis. 33, 305-311. doi: $10.1086 / 321886$ 
Roy, A., Eisenhut, M., Harris, R. J., Rodrigues, L. C., Sridhar, S., Habermann, S., et al (2014). Effect of BCG vaccination against Mycobacterium tuberculosis infection in children: systematic review and meta-analysis. BMJ 349:g4643. doi: 10.1136/bmj.g4643

Rybniker, J., Vocat, A., Sala, C., Busso, P., Pojer, F., Benjak, A., et al. (2015). Lansoprazole is an antituberculous prodrug targeting cytochrome bc1. Nat. Commun. 6:7659. doi: 10.1038/ncomms8659

Saribaş, Z., Kocagöz, T., Alp, A., and Günalp, A. (2003). Rapid detection of rifampin resistance in Mycobacterium tuberculosis isolates by heteroduplex analysis and determination of rifamycin cross-resistance in rifampin-resistant isolates. J. Clin. Microbiol. 41, 816-818. doi: 10.1128/JCM.41.2.816-818.2003

Schatz, A., Bugie, E., and Waksman, S. A. (1944). Streptomycin, a substance exhibiting antibiotic activity against Gram-positive and Gram-negative bacteria. Proc. Soc. Exp. Biol. Med. 55, 66-69. doi: 10.3181/00379727-55-14461

Scheetz, M. H., Knechtel, S. A., Malczynski, M., Postelnick, M. J., and Qi, C. (2008). Increasing incidence of linezolid-intermediate or -resistant, vancomycin-resistant enterococcus faecium strains parallels increasing linezolid consumption. Antimicrob. Agents Chemother. 52, 2256-2259. doi: 10.1128/AAC.00070-08

Selwyn, P. A., Hartel, D., Lewis, V. A., Schoenbaum, E. E., Vermund, S. H., Klein, R. S., et al (1989). A prospective study of the risk of tuberculosis among intravenous drug users with human immunodeficiency virus infection. N. Engl. J. Med. 320, 545-550. doi: 10.1056/NEJM198903023200901

Sensi, P. (1983). History of the development of rifampin. Rev. Infect. Dis. 5, S402-S406. doi: 10.1093/clinids/5.Supplement_3.S402

Sharma, S. K., Kohli, M., Yadav, R. N., Chaubey, J., Bhasin, D., Sreenivas, V., et al. (2015). Evaluating the diagnostic accuracy of Xpert MTB/RIF assay in pulmonary tuberculosis. PLOS ONE 10:e141011. doi: 10.1371/journal.pone.0141011

Shi, W., Zhang, X., Jiang, X., Yuan, H., Lee, J. S., Barry, C. E., et al. (2011). Pyrazinamide inhibits trans-translation in Mycobacterium tuberculosis. Science 333, 1630-1632. doi: 10.1126/science. 1208813

Skerry, C., Harper, J., Klunk, M., Bishai, W. R., and Jain, S. K. (2012). Adjunctive TNF inhibition with standard treatment enhances bacterial clearance in a murine model of necrotic TB granulomas. PLoS ONE 7:e39680. doi: 10.1371/journal.pone.0039680

Southwick, F. (2007). "Pulmonary infections," in Infectious Diseases: A Clinical Short Course, Vol. 104, 2nd Edn. (Florida, FL: McGraw-Hill Medical Publishing Division), 313-314.

Sowajassatakul, A., Prammananan, T., Chaiprasert, A., and Phunpruch, S. (2014). Molecular characterization of amikacin, kanamycin and capreomycin resistance in M/XDR-TB strains isolated in Thailand. BMC Microbiol. 14:165. doi: 10.1186/1471-2180-14-165

Subbian, S., Tsenova, L., O’Brien, P., Yang, G., Koo, M. S., Peixoto, B., et al (2011). Phosphodiesterase-4 inhibition alters gene expression and improves isoniazidmediated clearance of Mycobacterium tuberculosis in rabbit lungs. PLoS Pathog. 7:e1002262. doi: 10.1371/journal.ppat.1002262

Telenti, A., Imboden, P., Marchesi, F., Lowrie, D., Cole, S., Colston, M. J., et al (1993). Detection of rifampicin-resistance mutations in Mycobacterium tuberculosis. Lancet 341647-650. doi: 10.1016/0140-6736(93)90417-F

Telenti, A., Philipp, W. J., Sreevatsan, S., Bernasconi, C., Stockbauer, K. E., Wieles, B., et al (1997). The emb operon, a gene cluster of Mycobacterium tuberculosis involved in resistance to ethambutol. Nat. Med. 3, 567-570. doi: 10.1038/nm0597-567

Teo, S., and Shingadia, D. V. (2006). Does BCG have a role in tuberculosis control and prevention in the United Kingdom? Arch. Dis. Child. 91, 529-531. doi: 10.1136/adc.2005.085043

Tobin, D. M., Roca, F. J., Oh, S. F., McFarland, R., Vickery, T. W., Ray, J. P., et al (2012). Host genotype-specific therapies can optimize the inflammatory response to mycobacterial infections. Cell 148, 434-446. doi: 10.1016/j.cell.2011.12.023

Uhlin, M., Andersson, J., Zumla, A., and Maeurer, M. (2012). Adjunct immunotherapies for tuberculosis. J. Infect. Dis. 205, 325-334. doi: 10.1093/infdis/jis197

Vashisht, R., and Brahmachari, S. (2015). Metformin as a potential combination therapy with existing front-line antibiotics for tuberculosis. J. Transl. Med. 13:83. doi: 10.1186/s12967-015-0443-y
Velayati, A. A., Masjedi, M. R., Farnia, P., Tabarsi, P., Ghanavi, J., Ziazarifi, A. H., et al. (2009). Emergence of new forms of totally drug-resistant tuberculosis bacilli: super extensively drug-resistant tuberculosis or totally drug-resistant strains in Iran. Chest 136, 420-425. doi: 10.1378/chest.0 8-2427

Vilaplana, C., Marzo, E., Tapia, G., Diaz, J., Garcia, V., and Cardona, P. J. (2013). Ibuprofen therapy resulted in significantly decreased tissue bacillary loads and increased survival in a new murine experimental model of active tuberculosis. J. Infect. Dis. 208, 199-202. doi: 10.1093/infdis/jit152

Vilche'ze, C., and Jacobs, W. R. Jr. (2007). The mechanism of isoniazid killing: clarity through the scope of genetics. Annu. Rev. Microbiol. 61, 35-50. doi: 10.1146/annurev.micro.61.111606.122346

Volmink, J., and Garner, P. (ed). (2007). Directly observed therapy for treating tuberculosis. Cochrane. Database Syst. Rev. 29, 1-56. doi: 10.1002/14651858.CD003343.pub4

Waddington, K. (2004). To stamp out "So Terrible a Malady": bovine tuberculosis and tuberculin testing in Britain, 1890-1939. Med. Hist. 48, 29-48. doi: 10.1017/S0025727300007043

Wallis, R., Kim, P., Cole, S., Hanna, D., Andrade, B. B., Maeurer, M., et al (2013). Tuberculosis biomarkers discovery: developments, needs and challenges. Lancet Infect. Dis. 13, 362-372. doi: 10.1016/S1473-3099(13)70034-3

Wang, F., Langley, R., Gulten, G., Dover, L. G., Besra, G. S., Jacobs, W. R. Jr, et al. (2007). Mechanism of thioamide drug action against tuberculosis and leprosy. J. Exp. Med. 204, 73-78. doi: 10.1084/jem.20062100

Wang, L. Q., Falany, C. N., and James, M. O. (2004). Triclosan as a substrate and inhibitor of 30-phosphoadenosine 50-phosphosulfatesulfotransferase and UDP-glucuronosyl transferase in human liver fractions Drug Metab. Dispos. 32, 1162-1169. doi: 10.1124/dmd.104.000273

Wassersug, J. D. (1946). Pulmonary tuberculosis. N. Engl. J. Med. 235, 220-229. doi: 10.1056/NEJM194608152350704

Weber, A., Kaplan, M., Chughtai, S. A., Cohn, L. A., Smith, A. L., and Unadkat, J. D. (2001). CYP3A inductive potential of the rifamycins, rifabutin and rifampin, in the rabbit. Biopharm. Drug Dispos. 22, 157-168. doi: 10.1002/bdd.268

Wells, C. D., Cegielski, J. P., Nelson, L. J., Laserson, K. F., Holtz, T. H., Finlay, A., et al. (2007). HIV infection and multidrug-resistant tuberculosis-the perfect storm. J. Infect. Dis. 196, S86-S107. doi: 10.1086/518665

WHO (2006). Facts Sheet Fact Sheet $N^{\circ} 104$; Revised March 2006. Available online at :http: //www.who.int/tb/en/.

Williams, K. J. (2009). The introduction of "chemotherapy" using arsphenamine-the first magic bullet. J. R. Soc. Med. 102, 343-348. doi: 10.1258/jrsm.2009.09k036

Wolff, K. A., and Nguyen, L. (2012). Strategies for potentiation of ethionamide and folate antagonists against Mycobacterium tuberculosis". Expert Rev. Anti Infect. Ther. 10, 971-981. doi: 10.1586/eri.12.87

Wolucka, B. A. (2008). Biosynthesis of D-arabinose in mycobacteria -a novel bacterial pathway with implications for antimycobacterial therapy. FEBS J. 275, 2691-2711. doi: 10.1111/j.1742-4658.2008.06395.x

Working Group on New TB Drugs (2010). The Global TB Drug Pipeline. Available online at: http://www.newtbdrugs.org/project.php?id5183\T1 \ae.

World Health Organization (2009). Global Tuberculosis Control: Surveillance, Planning and Financing, WHO/HTM/TB/2009.411. Geneva: WHO.

World Health Organization (2010). Multidrug and Extensive Drug Resistant Tuberculosis: 2010 Global Report on Surveillance and Response. Geneva: WHO.

World Health Organization (2014). Global Tuberculosis Report. Geneva: WHO. WHO/HTM/TB/2014.08

Yan, L., Gao, L., Cui, Z., Hu, Z., Lu, J., Shen, X., et al. (2015). Investigation of cross-resistance between Rifampin and Rifabutin in multidrug resistant Mycobacterium tuberculosis. Med. Chem. 5, 412-414. doi: 10.4172/2161-0444.1000293

Zhang, Q., Liu, Y., Tang, S., Sha, W., and Xiao, H. (2013). Clinical benefit of delamanid (OPC-67683) in the treatment of multidrug resistant tuberculosis patients in China. Cell Biochem. Biophys. 67, 957-963. doi: 10.1007/s12013-013-9589-5

Zhang, Y., Wade, M. M., Scorpio, A., Zhang, H., and Sun, Z. (2003). Mode of action of pyrazinamide: disruption of Mycobacterium tuberculosis membrane transport and energetics by pyrazinoic acid. J. Antimicrob. Chemother. 52, 790-795. doi: 10.1093/jac/dkg446 
Zink, A., Sola, C., Reischl, U., Grabner, W., Rastogi, N., Wolf, H., et al. (2003). Characterization of Mycobacterium tuberculosis complex DNAs from Egyptian mummies by spoligotyping. J. Clin. Microbiol. 41, 359-367. doi: 10.1128/JCM.41.1.359-367.2003

Zumla, A., Hafner, R., Lienhardt, C., Hoelscher, M., and Nunn, A. (2012). Advancing the development of tuberculosis therapy. Nat. Rev. Drug Discov. 11, 171-172. doi: 10.1038/nrd3694

Zumla, A., Nahid, P., and Cole, S. T. (2015). Advances in the development of new tuberculosis drugs and treatment regimens. Nat. Rev. Drug Discov. 12, 388-404. doi: $10.1038 / \mathrm{nrd} 4001$
Conflict of Interest Statement: The authors declare that the research was conducted in the absence of any commercial or financial relationships that could be construed as a potential conflict of interest.

Copyright (๑) 2017 Al-Humadi, Al-Saigh and Al-Humadi. This is an open-access article distributed under the terms of the Creative Commons Attribution License (CC $B Y)$. The use, distribution or reproduction in other forums is permitted, provided the original author(s) or licensor are credited and that the original publication in this journal is cited, in accordance with accepted academic practice. No use, distribution or reproduction is permitted which does not comply with these terms. 